\title{
Comparative Research on Tourism Industry Features of Wuyuan in Jiangxi and Nanshan in Yantai
}

\author{
Qing Li \\ Art and Design of School of Humanities \\ Yantai Nanshan University \\ Yantai, Shandong, China 265713
}

\begin{abstract}
Known as "The most beautiful village in China", Wuyuan County in Jiangxi Province builds itself as the most powerful county in China's tourism field in just a dozen years by virtue of antique and traditional Hui style architecture with a long history, incomparable historical culture resource of long standing, familiar and unique tourism featured commodities and widely known tourism publicity strategy arousing sensation both at home and abroad. It does not come singly, but in pairs. With respect to development of Wuyuan's tourism, Yantai Nanshan tourism attraction has no culture labels like Wuyuan, such as "The 50 places necessary to go during a lifetime", and "Flower sea Wuyuan" and so on. Instead, it realizes the deep cross from $4 \mathrm{~A}$ to $5 \mathrm{~A}$ tourism attraction by virtue of beautiful humanity architecture landscape, advantaged religious cultural resource, and international tourism vacation zone integrated with sightseeing tour and leisure and recreation. If seeing finely, their tourism development patterns can be said as ancient and modern, and Chinese and western, having both distinctions and mutual learning advantages. Powerful features appear during study on tourism development process of Wuyuan in Jiangxi and Nanshan in Yantai. These features can create complementary advantages during development of their tourism and will have positive enlightening effects on development of tourism in various places.
\end{abstract}

Keywords-Wuyuan; Nanshan; culture; tourism

\section{INTRODUCTION}

As a mountainous county, Wuyuan belongs to Shangrao, which is in the northeast of Jiangxi Province. Depending on beautiful natural landscape scenery and profound cultural deposits, it develops from an unknown desolate mountainous county into a strong ecotourism county of leisure agriculture and rural tourism, opens up a successful development road for rural tourism and injects fresh vitality into development of tourism industry. Here in Wuyuan, you can appreciate rape flower sea all over the mountains and plains in Jiangling's spring, give ear to gurgling water of running creek under the bride resident in Likeng's summer, experience residents' harvest joy in Huangling's fall, and appreciate Mandarin ducks in Mandarin Ducks Viewing Pavilion which is as clear and blue as jade. Apart from these natural landscapes, ancient buildings and exquisite wood engravings are all telling the prosperous writing style here. They become the cohesion and symbol of Wuyuan's long history, attracting people to step on this piece of ancient land and to experience another kind of dream world and feeling. What's more, people here are simple and honest, green hills look like women's eyebrows, places of interest are everywhere and ancient Huizhou's smart spirit is saved. Therefore, people call it "Homeland of Chinese traditional culture". Green hills and clear waters are studded with pavilions and wharf wall with cornice and rake angle. Seeing from far distance, they look like vivid Chinese ink painting which is full of artistic conception, making stopped tourists too delighted to leave.

Compared with native-born original ecological tourism resources of Wuyuan, Nanshan scenic spot in Longkou Port, Yantai, Shandong is the combination of modernity and culture. After abundant exploration and argument on tourism industry, powerful Nanshan Group resolutely spends huge money in building a large comprehensive tourist resort near Lushan, integrating tourism, sight-seeing, leisure, vacation, commerce and fitness. Apart from excavating remaining religious resource and building Chinese Historic Cultural Park and Religious Cultural Park, the unrivalled tin bronze giant Buddha is also built in the scenic spot, containing Buddhist culture in tourism resource. It is misty here throughout the year, and pilgrims here are like clouds. The believers come with each other to make a wish or go hiking. Ancient temple, Taoist temple and zen temple built on the hillside are all covered in a layer of mysterious color, and ancient architectural complex full of modern sense displays more romantic charm.

\section{COMPARATIVE ANALYSIS ON ARCHITECTURAL STYLE} OF WUYUAN IN JIANGXI AND NANSHAN TOURIST ATTRACTION IN YANTAI

As everyone knows, Wuyuan is one of the birthplaces of Hui culture, therefore the ancient buildings here belong to Hui style architecture in general. A large number of ancient buildings are well saved here, which can be called model of Hui style architecture. In Ming and Qing Dynasties, Huizhou merchants here mainly deal in tea, wood and salt, and their footprints spread on both sides of the Yangtze River. Powerful and rich Huizhou merchants go in for large-scale construction. They build ancestral halls, stages, tea houses, inns and other ancient buildings to glorify and illuminate the ancestors, demonstrating the clan's prosperity and flourish. Commercial tycoons' sparing no effort and impetus of established family from Central Plains contribute to prosperity and flourish of Hui style architecture here. Looking ahead, in mist-shrouded atmosphere, pure white wall and black tiles crawl in pieces or 
are scattered fragmentarily in winding landscape. Architecture for humanity and natural landscape blend together, poetic and picturesque. After baptism of several hundred years, a few walls of some ancient buildings have fallen off, bringing out the best in blue flagstone road washed by rain and adding the sense of simplicity, nature, elegance and freshness in mottlement and shadow. Wharf wall with ups and downs in cascade is the most evident feature of Hui style architecture. They raise their head and look, increasing the building group's magnificent momentum and rhythm. The wharf wall's cornice and rake angle and soaring white wall, and mottled wall and stream which is as pure and white as Chinese Juan form intense comparison, demonstrating contrast of form, color and quality in ancient architecture with harmony and unity. There are also changes in unity.

Different from Hui style architecture in Wuyuan, building group in Nanshan scenic spot has a series of unified macro planning, therefore atmosphere of humanism and coherence are more intense. Lushan is in circum-Bohai-Sea district. Seaview buildings facing the ocean are also included in Nanshan's tourism landscape and sea light and mountains satisfy people's yearn for ocean. Apart from mountainous zen temples, Taoist temples, Buddha halls and other religious buildings in Religious Cultural Park and Historic Cultural Park in Nanshan scenic spot, they also build a large-scale theme park--Happy Canyon, inside which there is modern fashionable Nanshan waterfall, saddle club, pet park, happy island, Nanshan yard in quadrangle dwellings style and other scenic spots. Nanshan yard reproduces ancient Huang County's gray brick and tile, plastered wall and red window. The yard is axisymmetric. Exquisite wood craving and stone craving on aisle column are decorated with vigorous calligraphy in style. Shop, wind workshop, pawnshop and other ancient buildings in ancient Huang County are fully reproduced here. Cast copper sculpture and farming utensil which display ancient Huang County's local customs and practices are true to life, well annotating life of rich family and croft and eastern Shandong civilization here. There is ride in the whirlwind, large-scale slide and other entertainment facilities combing participation, recreation and experience in happy island with strong modern sense.

Ancient architecture complex in Wuyuan and Nanshan is built on the basis of original natural resource. Being good at protection and inheritance is their common character and our attitude towards original ecological landscape. The feature of Wuyuan's architecture is "ancient", and the feature of Nanshan's is "inheritance". One is ancient and one is modern, each having its own merits. After appreciating authentic Hui style architecture, it is really fabulous to experience human landscape with modern sense in Nanshan.

\section{COMPARATIVE ANALYSIS ON TOURISM CULTURE OF WUYUAN IN JIANGXI AND NANSHAN IN YANTAI}

Wuyuan County has been established for more than 1200 years with historical culture of long standing and breeds unique traditional opera culture, geomancy culture, tea culture, bridge culture, religious culture and so on, which are great property inherited from forefathers of Wuyuan. They together form up complete and enormous Hui culture system and permeate into every aspect of Wuyuan laboring people's life in philosophy, psychology, behavior and so on, having a farreaching influence. When mentioning traditional opera culture, we have to talk about the unique ancient stage in Wuyuan. People in Wuyuan show special preference to stage. No matter it is wedding, funeral, festival or praying, people invite famous actors from Jiangsu and Zhejiang to perform operas. If clansmen violate the law and discipline, stage becomes the place for the clan to practice domestic discipline, having education and caution effect. Whenever there is traditional opera performance, villagers kill pigs and sheep, friends and relatives invite each other to see opera together and make judgments on plot and characters in the opera happily. What an extremely lively scene. Apart from being the carrier for people's pursuit of spiritual culture, ancient stage is also the symbol of people's social status. After flourishing, apart from promoting their social status through becoming official gentry by imperial examination, Hui merchants also make friends with writers and poets through widely constructing opera stages and playing traditional opera, thus demonstrating their elegant taste and promoting their social status. Therefore, step on the land of Wuyuan and ancient opera stages of various styles will intrude into people's eyes by accident, telling previous prosperity and noise. Rainbow bridge built in Southern Song is also a famous scenic spot in Wuyuan and tourists scramble for it. Maybe they are unknown that there are 320 bridges over rivers here and each ancient bridge has a sad or beautiful legend, which is the reflection of Wuyuan people's spiritual culture and forms the age-old bridge culture. The ancient bridges here are exquisitely and finely craved with graceful figure or simple and unadorned and unknown to public. They can always make tired people in hasty steps stop to listen to loquacious sound of stream. In ancient times, people pray to gods for their wish. If the wish comes true, they will empty their pocket to build bridges, in which way to repay gods. Therefore, ancient bridges which go through all the vicissitudes of life are also the proof of Wuyuan people's accumulating virtue and well doing.

As national 5A tourist attraction, constructers in Nanshan constantly inject connotation of happiness and longevity culture, religious culture and folk culture into it during the development of expanding Nanshan's tourism industry. They depict a harmonious scene of "happiness and longevity Nanshan, heaven for nourishing heart" with overwhelming strategies and great courage. With arrival of China's aging society, provision for the aged occupies people's attention in general. It displays Nanshan Group's feelings of compassion in concerning the society and emphasis in individual life to bring old people's health wellness into Nanshan tourism culture's frame. Construction of international leisure and rest center and college for the aged in Nanshan satisfies old people's physical and spiritual health and spare-time cultural life. Old people truly live joyfully with dignity and prolong life joyfully in Nanshan through participating in golf, fishing, painting and calligraphy, chess and card courses. Beside happiness and longevity culture, religious culture is also one of the connotations of Nanshan tourism culture. The left hand and right hand of Buddha in Nanshan Religious Cultural Park respectively do "grant of wish seal" and "grant of courage seal", expressed as removing pain for all living things in the 
world and take across sentient beings universally. The Buddha and 9999 figures of Buddha in Ten Thousand Buddhas Monastery under lotus agora form magnificent battle array of ten thousand Buddhas together, advocating people to abandon evil and promote kindness, emphasize on culture in heart and look for spiritual conversion. Nanshan can yet be regarded as the home for soul for people with increasing life pressure.

Without a doubt, as outstanding performers in development of tourism industry, Wuyuan and Nanshan pay great attention to exploration and moulding of their own cultural connotation, which can truly subside in people's heart after appreciating natural view and can take root and sprout in people's heart and make performances in action. In today's rapid development of tourism industry, competition in physical form has become competition of culture. Making efforts in exploring one's own cultural factor and making it big and deep provide great competitiveness for development of tourism in various places.

\section{COMPARATIVE ANALYSIS ON FEATURED TOURISM COMMODITIES OF WUYUAN IN JIANGXI AND NANSHAN IN YANTAI}

Since ancient times, Wuyuan has the reputation of "land of tea" and "land of calligraphy". Green tea, dragon's tail, Nuo dance mask, pouch carp, daisy in Xiaoqi, and wood craving and paper umbrella in Jialu are known far and wide and they satisfy tourists" "purchase" need. After finishing travel to Wuyuan, they can still experience the unique folk culture here. Therefore, tourist commodities are extension of tourism culture and have intangible publicity effect. Due to original mountainous natural environment in Xiaoqi, Wuyuan, the daisy here are naturally mellow. After brewing in glass, the flower bursts into blossom with golden yellow soup and fragrance striking the nostrils, which is really beautiful. Apart from making tea to drink, daisy also has the medicinal value of liver protection and improving eyesight. Therefore, it is regarded as the top grade tea by observant and conscientious people who cherish and love tea. It is thus clear that it is not groundless that Guangxu Emperor regards "Xiaoqi daisy" as auspicious sign of the nation and grants its name. In addition, Osmanthus fragrans tea titled as "Wuyuan green tea" in Yan Mountain and pear garden tea in Xitou have been used as articles of tribute and pushed into international market by tea professors in Wuyuan. They receive appreciation from consumers both at home and abroad. Teamen with elegant taste make friends through drinking tea and add brilliance to present splendor of Wuyuan's tourism development. She inkstand is one of the four famous inkstones in China. The ones made by stone material from brookside of Dragon's Tail Mountain, Wuyuan have the highest quality. Therefore, she inkstone is also called dragon's tail inkstone. Scholars praise it as: Its color is like jade, has gorgeous texture, and grinds without a sound. It is cherished by celebrities and painters from various places. In addition, paper umbrella in Jialu uses sophisticated materials with exquisite workmanship, and it wins women's deep love. Therefore, featured commodities in Wuyuan are to numerous to name one by one. It is not excessive to use a land of plenty to describe it.

Nanshan manor red wine is the featured tourist commodity in Nanshan scenic spot, and it is a famous brand product developed by Yantai Nanshan Manor Wine Co., Ltd under Nanshan Group and it has obtained certification of national green product and national quality inspection exemption certificate. Located in Nanshan Buddha tourist attraction, this wine company is a manor-typed modern wind manufacture enterprise which combining grape planting, wine making, tour and sightseeing and wine culture. In order to guarantee quality of wine, the company introduces the most advanced international wine production equipment, full-automatic filling line and French high quality oak barrel at present from abroad. Fully furnished and advanced in technique, it researches and develops Nanshan manor dry red wine and iced white wine series products, more than 60 kinds in total successively, winning consumers' love. Nanshan Group always stick to striving for survival on the basis of quality and constant innovation, thus Nanshan manor wine's reputation in society grows with each passing day. In addition, based on natural tepid climatic environment in Longkou Port, Longkou silk noodles, Longkou lobster, Sandoy trepang and Longkou strawberry are all popular commodities in Nanshan tourist attraction which are famous both at home and abroad and win deep love from tourists. As geographical indication product, Longkou silk noodles sell well in over 60 countries and regions, like America and Japan, enjoying good fame both at home and abroad; "Stichopus japonicus" produced around Sandoy sea area in Longkou contains several kinds of microelements and it is a famous product in eastern Shandong.

It is obvious that featured commodities of the two places both develop on the basis of natural regional resource, and unexceptionally experience deep processing and achieve having merits others do not have and being more exquisite in common parts. Featured commodities are cultural label of sightseeing place. They can promote increase of tourism economy and have propagandistic effects. Therefore, every sightseeing place pays great attention to development of tourist commodity. It should be noted that, beside maintaining the product's pre-existing personality and features, we should also try every means to promote product's added value of technology and pursue unity of art and technique.

\section{COMPARATIVE ANALYSIS ON TOURISM PROMOTION} STRATEGY OF WUYUAN IN JIANGXI AND NANSHAN IN YANTAI

With start of "China's most beautiful countryside" brand strategy, Wuyuan people have established brand promotion sense. Apart from using traditional media, they also fully use website, forum and microblog to promote, like Most Beautiful Wuyuan Travel Network, Wuyuan Travel Official Website and China Wuyuan Website. They introduce tourism features and hot spots of Wuyuan to travel enthusiasts comprehensively in multi-angles; Organize "The most beautiful Wuyuan" international photography exhibition to attract people; Another example, large groups of art school students and painters fall into company with each other to come here to do painting in the cool autumn breeze season, which itself is a bright human landscape, further enriching humanistic connotation here.

Compared with Wuyuan's abundant promotion means, Nanshan tourist attraction is pale. Although spring temple fair, golf masters tournament and tourism cultural festival are competitive in each year, they are lack of new conception. 
Department of Art Design in Nanshan University which also belongs to Nanshan Group organizes students to do exploration and painting in tourist attraction. They seek far and neglect what lies close at hand, and travel to Wuyuan or Taihang Mountains, neglecting Nanshan landscape around the corner. If the tourist attraction can be free to students, showing of vivid landscape works of students on the internet can be very good promotion for Nanshan tourist attraction. In addition, Wuyuan uses film and television and celebrities to promote its popularity, which can be imitated by Nanshan scenic spot. Apart from shooting micro films with Nanshan as the carrier in Nanshan film base or animation department at school, it can also cooperate with famous TV stations or websites to improve popularity of the scenic spot.

In conclusion, powerful features displayed in tourism industry development of Wuyuan, Jiangxi and Nanshan, Yantai both have common point and mutual learning point. They two can complement each other's advantages, enlightening development of tourism industry in various places.

\section{REFERENCES}

[1] Hong Wangyuan. Reflections on Development of Culture and Tourism Resources in Wuyuan[J]. Jingdezhen Comprehensive College Journal.2014(6)

[2] Zhang Yingying. Existed Problems and Development Strategy Research on Wuyuan Ecotourism[J].Regional Economy.2014(6). 